\title{
ARTICLE OPEN Severe effects of long-term drought on calcareous grassland seed banks
}

\author{
Sofía Basto $\mathbb{D}^{1}$, Ken Thompson ${ }^{2}$, J. Philip Grime ${ }^{2}$, Jason D. Fridley ${ }^{3}$, Sara Calhim ${ }^{4}$, Andrew P. Askew ${ }^{3}$ and Mark Rees (D) $^{2}$
}

Climate change models project shifts in precipitation patterns at regional and global scales. Increases in dry areas and the occurrence of drought predicted in future scenarios are likely to threaten grassland ecosystems. Calcareous grassland seed banks have proven to be resistant to short-term drought, but their responses to long-term drought are unknown. Here we show that 14 years of summer drought changed calcareous grassland seed bank composition, reducing its size and richness, and that these responses do not simply reflect patterns in the above-ground vegetation. Moreover, the effect of drought was larger on seed banks than on vegetation, and above-ground responses mediated by soil depth were less evident in the seed bank than in the vegetation. These results demonstrate that the severity of drought effects on calcareous grasslands is larger than previously thought, and show that this ecosystem is highly vulnerable and has low resilience to predicted decreases in soil moisture.

npj Climate and Atmospheric Science (2018)1:1 ; doi:10.1038/s41612-017-0007-3

\section{INTRODUCTION}

Climate change has impacted ecosystems on all continents, especially in recent decades, and has been attributed, in part, to changes in precipitation patterns. ${ }^{1}$ Shifts in rainfall constitute a major threat to some highly biodiverse ecosystems, such as seminatural grasslands. ${ }^{2}$ Because the amount and timing of rainfall have large effects on several biological processes in grasslands, ${ }^{3}$ changing quantities and patterns of precipitation alter the composition of their plant communities ${ }^{4-6}$ and reduce their productivity. ${ }^{7}$ This is concerning because grassland is one of the most widespread biomes in the world, supporting many endemic species. $^{8}$ Specifically, calcareous grasslands are among the most diverse and threatened plant communities in Europe,, 90 containing between 20 and 50 different vascular plants per square metre, many of them rare or threatened. ${ }^{9}$ Therefore, calcareous grassland is an ecosystem of high conservation value ${ }^{10,11}$ and high aesthetic appeal. ${ }^{11}$ Understanding its resilience to environmental change is essential for conservation strategies. ${ }^{10}$ Nevertheless, predictions of how grassland communities will respond to altered precipitation regimes are limited by the lack of understanding of these inherently complex ecosystems ${ }^{3}$ and species-specific responses. ${ }^{12}$ This lack of understanding is particularly problematic for the soil seed bank. ${ }^{13}$

Although altered precipitation regimes, in the context of climate change, may have direct influences on seed size and seed bank persistence, ${ }^{14}$ predicting the effects of changes in rainfall patterns on seed longevity and consequently on seed banks is difficult. This is due to the complexity of the relationships between soil moisture content and seed longevity, ${ }_{1}^{15}$ and between rainfall and other environmental variables. ${ }^{13}$ There has been little work focussing on potential direct effects (i.e. on seed viability and longevity) of altered precipitation regimes on grassland seed banks, and research has generally addressed the effects of temperature shifts. ${ }^{16}$ Moreover, most studies have been limited to short-term effects. ${ }^{17,18}$ For example, a seed burial study conducted on calcareous grasslands found no evidence of any direct effect on seeds after 2 years of additional summer rainfall and winter warming. ${ }^{18}$ In addition, another 6-year study did not find significant evidence for any direct effect of summer drought on seed banks. ${ }^{17}$ However, so far, the effects of long-term altered precipitation regimes on grassland seed banks have not been quantified. Because the consequences of drought may be detected only after several decades, ${ }^{19}$ there is a possibility that only after prolonged changes in precipitation will there be noticeable effects on the seed bank. ${ }^{17}$

More attention has been paid to the indirect effects of changes in precipitation patterns on grassland seed banks. First, germination in response to soil moisture is species-specific, ${ }^{20-22}$ with moisture affecting both the percentage and speed of germination $^{20}$ or having a weak effect buffered by soil type. ${ }^{22}$ Second, changes in rainfall might modify the soil microbial community, which is the primary cause of seed death for some grassland species. ${ }^{23,24}$ For example, the combination of additional summer rainfall and winter warming had no significant direct effect on seed banks after 2 years, but the seed longevity of some grassland species tested was increased by applying fungicides. ${ }^{18}$ These results indicate a possible effect of climate change on soil microorganisms and indirectly on seed banks. Third, aboveground responses may affect seed bank structure. For instance, vegetation responses to 3 years of reduced precipitation led to increased similarity between above- and below-ground populations. ${ }^{5}$ Another study has shown that the Arabidopsis thaliana seed bank increased after 6 years of summer drought, possibly as a consequence of the creation of vegetation gaps which facilitated the expansion of this species by increasing plant survival and seed production. ${ }^{17}$ Nevertheless, so far it has not been tested if the

\footnotetext{
${ }^{1}$ Unidad de Ecología y Sistemática, Departamento de Biología, Facultad de Ciencias, Pontificia Universidad Javeriana, Carrera 7 No. $43-82$ Ed. Jesús Emilio Ramírez (53), Bogotá, Colombia; ${ }^{2}$ Department of Animal and Plant Sciences, University of Sheffield, Western Bank, Sheffield S10 2TN, UK; ${ }^{3}$ Department of Biology, Syracuse University, 107 College Place, Syracuse, NY, USA and ${ }^{4}$ Department of Biological and Environmental Science, University of Jyväskylä, PO Box 35, Jyväskylä FI-40014, Finland Correspondence: Sofía Basto (sbasto@javeriana.edu.co)
} 

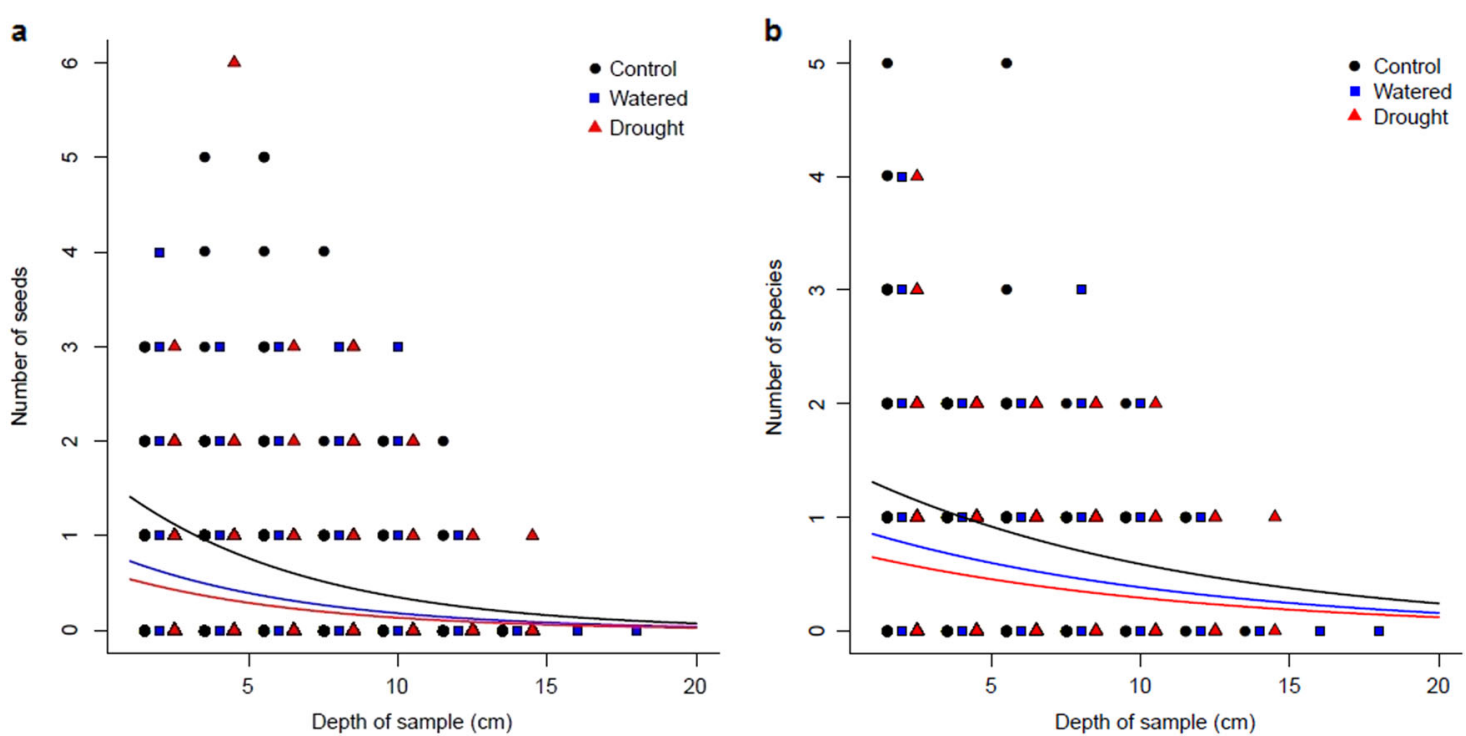

Fig. 1 Effect of altered precipitation regimes on seed banks of a calcareous grassland after 14 years of precipitation shifts at Buxton. a Number of seeds. b Number of species. The long-term summer drought reduced the total seed abundance and species richness. Across all the treatments, the number of seeds $\mathbf{a}$ and species $\mathbf{b}$ declined with increasing soil sample depth. The figure shows the scatter plots with the fitted curves

effects of long-term altered precipitation regimes on aboveground flora are reflected in the seed bank or if seed bank responses are largely independent.

Understanding the indirect effects of altered precipitation regimes on seed banks, via the above-ground vegetation, is challenging as vegetation responses are modified by other environmental factors. Above-ground studies have revealed that plant responses to altered precipitation regimes are mediated by micro-topographic or micro-environmental effects. ${ }^{25-27}$ Specifically, in calcareous grasslands resistance is linked to community reorganization at the microsite level facilitated by soil depth. ${ }^{26}$ For example, at the Buxton Climate Change Experiment (England, UK), some species have moved to areas of deeper soil while others have moved to shallower soil in response to long-term precipitation treatments. ${ }^{26}$ Similar responses have been recorded in southwestern Belgium, where populations growing on shallow soils were less buffered against drought compared with those occurring on deeper soils. ${ }^{28}$ However, it is not known whether seed banks show similar responses, which would occur as a consequence of a reorganisation of the seed bank according to soil depth (i.e. species changing distribution in response to altered precipitation regimes).

Here, we investigate the effects of 14 years of altered precipitation regimes on the size, composition and richness of the seed bank in calcareous grassland plots in the Buxton Climate Change Impacts Laboratory (BCCIL) at Harpur Hill, a site near Buxton, UK. The BCCIL has been conducting one of the longestrunning studies about the effects of climate change on the calcareous grassland structure, composition and function; ${ }^{29}$ in fact, this is the second longest-running experiment in the world about the impacts of climate alteration on semi-natural vegetation. ${ }^{30}$ Annual rainfall and temperature regimes have been manipulated, since 1993, based on the predictions for climate change in the UK by $2080 .{ }^{29}$ At the plot scale $\left(9 \mathrm{~m}^{2}\right)$, the vegetation of this calcareous grassland showed resistance to precipitation shifts. ${ }^{29}$ However, at small scales $\left(100 \mathrm{~cm}^{2}\right)$, studies revealed that the stability of this plant community was mediated by soil heterogeneity, specifically the marked spatial variation in soil depth recorded in the experimental site. ${ }^{26}$ Here, we examine the longterm effects of both increased and reduced rainfall, and the role of both above-ground flora responses and variation in soil depth on seed banks. We expect our results to enhance our understanding of the effects of climate change on ecosystems. Seed banks represent biodiversity reservoirs for grasslands and other ecosystems on a global scale, ${ }^{31}$ playing an important role in the maintenance of genetic and species diversity, ${ }^{32,33}$ and in the reestablishment of species lost from the above-ground vegetation. $^{34}$ Moreover, they reduce the risk of extinction as a consequence of a single environmental event such as drought or flooding. ${ }^{35}$ Therefore, seed banks are often thought to buffer the responses of plant communities to climate variation, ${ }^{36}$ providing potential resilience to disturbance or environmental shifts, ${ }^{31}$ and to decrease extinction vulnerability under climate change. ${ }^{37}$ It is therefore crucial to discover whether these assumptions are correct for calcareous grassland communities.

\section{RESULTS}

Seed bank size and richness

There was no significant effect of long-term supplemental summer rainfall on calcareous grassland seed bank size or richness $(P>0.1$ in all cases). However, total abundance of the seed bank was reduced by $37 \%$ after 14 years of summer drought (GLMM; estimate \pm s.e. of the estimate of the fixed effect parameter in the model $=-0.46 \pm 0.13 ; z$-test $=-3.5, P<0.001)$ (Fig. 1a), and drought reduced species richness by $29.2 \%$ (GLMM; $-0.35 \pm 0.13 ; z=-2.7, P<0.01$ ) (Fig. 1b). Drought had a significant effect on seed bank composition (treatment was significantly correlated with the NMDS ordination structure, $r^{2}=0.49, P<0.001$, Fig. 2); of the 23 species recorded in the seed bank, the drought and control treatments had only 9 species in common (Table 1). Seed bank size and richness decreased significantly with increasing soil sample depth across all the treatments (GLMM; $-0.09 \pm 0.02 ; z=-5.7, P<0.00001$ and $-0.09 \pm 0.02 ; z=-5, P<$ 0.00001 respectively) (Fig. $1 \mathrm{a}, \mathrm{b})$.

Functional groups and the most abundant species

There was no significant effect of supplemental summer rainfall on the abundance of any functional group (grasses, sedges, forbs) or the most abundant species ( $P>0.1$ in all cases). However, summer drought significantly reduced seed bank abundance of forbs by $32.3 \%$ and sedges by $78 \%$ (GLMM; $-0.39 \pm 0.15 ; z=-2.7$, 


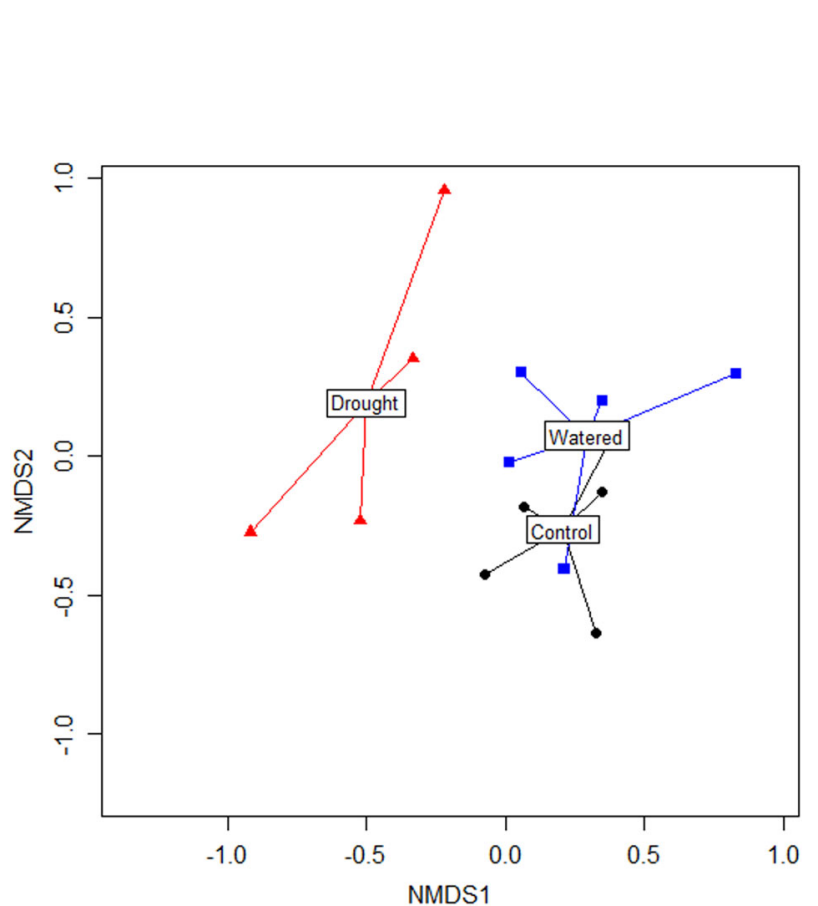

Fig. 2 Two-dimensional non-metric multidimensional scaling (NMDS) ordination of seed banks after 14 years of altered precipitation regimes at Buxton, UK. Ordination is based on species abundance data; there were 5 plots in each treatment. Text shows centroids for precipitation treatments. The lines connect plots points to their centroids. The ordination analysis confirmed a difference between seed bank communities in control plots and those under drought
$P<0.01$ and GLMM; $-1.5 \pm 0.5 ; z=-3.1, P<0.01$ respectively), but there was no effect of drought on grass seed abundance (GLMM; $-0.35 \pm 0.4 ; z=-0.9, P=0.4)$. Among the two most abundant species in the seed bank, the abundance of $H$. pulchrum was reduced by drought by $42 \%(G L M M ;-0.54 \pm 0.18 ; z=-3, P<0.01)$, while the size of the $C$. rotundifolia seed bank became more than double in the drought treatment (GLMM; $1.1 \pm 0.4 ; z=3, P<0.01$ ). Carex pulicaris, C. panicea and Potentilla erecta were not abundant enough in the seed bank to be analysed separately, but were notably absent from the plots under drought.

Across all treatments, fewer seeds of forbs (GLMM; $-0.06 \pm 0.02$; $z=-3.5, \quad P<0.001)$, sedges (GLMM; $-0.31 \pm 0.07 ; \quad z=-5, \quad P<$ $0.00001)$ and grasses (GLMM; $-0.1 \pm 0.04 ; z=-2.6, P<0.01)$ were recorded with increasing soil sample depth. There was also a marginally significant decrease in the abundance of $H$. pulchrum as soil sample depth increased (GLMM; $-0.04 \pm 0.02 ; z=-2, P=$ $0.051)$, but the number of seeds of $C$. rotundifolia did not vary with sample depth (GLMM; $-0.05 \pm 0.05 ; z=-1, P=0.34$ ).

Relationship between vegetation and seed bank

Both vegetation and seed bank species composition were changed significantly by drought $\left(r^{2}=0.92, P<0.001\right)$ (Fig. 3). Moreover, the similarity between the seed bank and the aboveground plant community under drought was reduced (Supplementary Fig. 1); under this treatment, of the 31 species recorded in the standing vegetation, only 8 were recorded in the seed bank (Supplementary Table 1). Overall, the result of NMDS showed that species composition of seed banks and vegetation above-ground were different. The first axis clearly separated seed bank from

Table 1. Species composition of seed banks in calcareous grassland soil under different precipitation treatments at Buxton (Derbyshire)

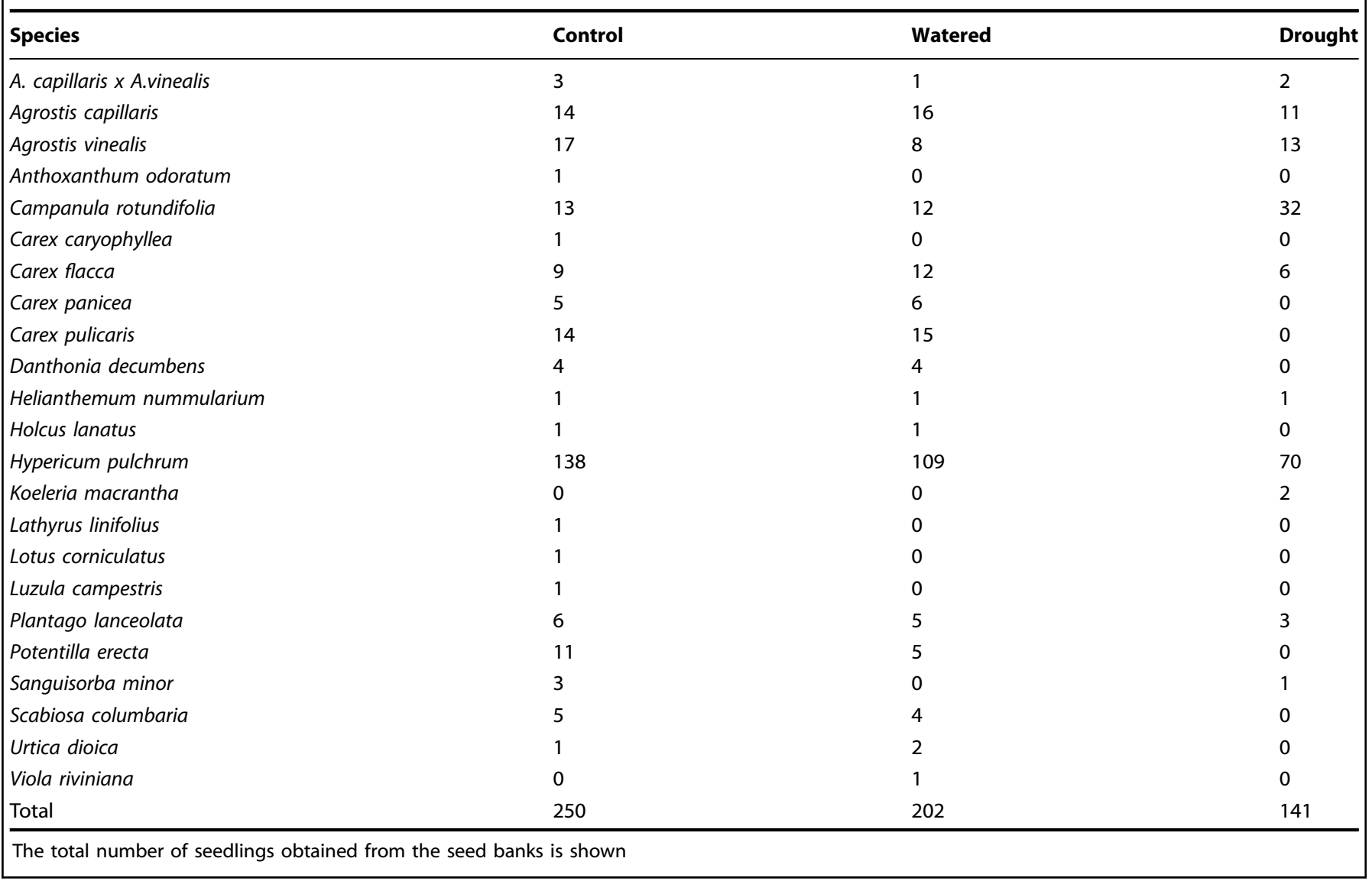




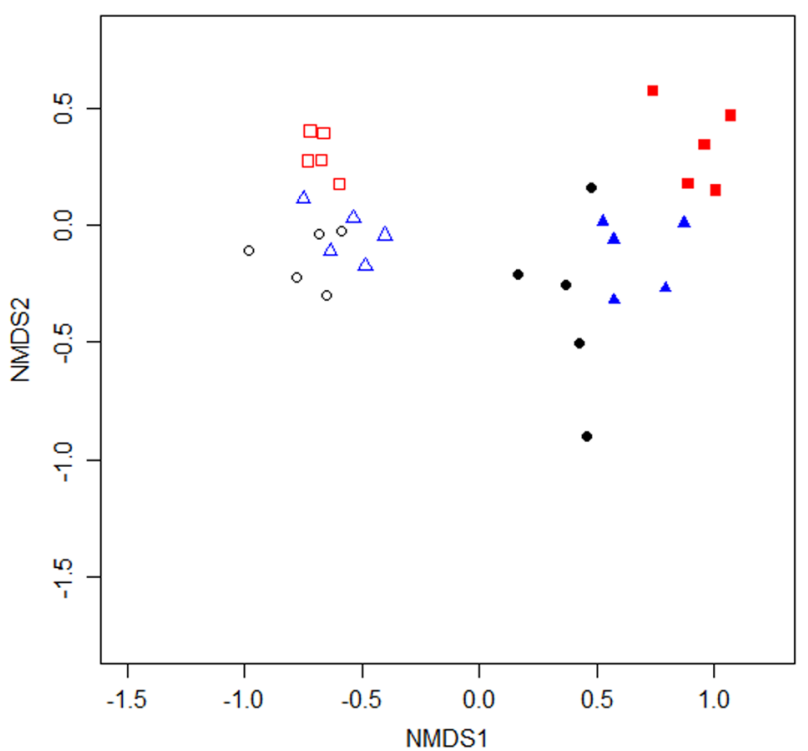

Fig. 3 Two-dimensional nonmetric multidimensional scaling (NMDS) ordination of seed banks and above-ground vegetation after 14 years of precipitation changes at Buxton, UK. Open symbols represent above-ground vegetation data and closed symbols seed bank data. Treatments are represented by colours: black $=$ control, blue $=$ watered and red $=$ drought. Ordination is based on the relative abundance of species data. There were 5 plots in each treatment. The location of ordination points indicates the degree of similarity between each one. The ordination confirmed a difference between seed bank and above-ground vegetation communities

vegetation (Fig. 3). Across all precipitation treatments 18 species were recorded in both communities (Supplementary Table 1). These differences in species composition were also consistent with the fact that there was no significant effect of the number of species above-ground on below-ground species richness (GLM; $0.04 \pm 0.06 ; z=0.7 ; \mathrm{df}=1,11 ; P=0.49$ ). Moreover, the relative abundance of species in the vegetation was not related to the relative abundance of seeds in the soil (GLM; $P>0.05$ in all cases). In addition, although the seed banks of both $H$. pulchrum and $C$. rotundifolia were significantly affected by reduced precipitation, above-ground vegetation cover of neither of these species was affected significantly by altered precipitation regimes (GLM; $P>$ 0.05 in all cases). The distribution of treatments along the second axis of the NMDS shows that changes in both the vegetation and seed bank were aligned similarly, although there is a suggestion of a diverging trend (Fig. 3). This is reflected in the species composition; in the control, vegetation and seed bank had 16 species in common, while this was reduced to 8 under drought (Supplementary Table 1).

Seed bank distribution in relation to soil depth

There was no effect of spatial variation in soil depth on seed bank species richness or abundance $(\mathrm{GLMM} ; 0.001 \pm 0.01 ; z=0.15, P=$ 0.88 and GLMM; $0.006 \pm 0.01 ; z=0.7, P=0.5$ respectively). Moreover, the abundance of forbs, sedges, $C$. rotundifolia and $H$. pulchrum did not change along a gradient of soil depth (GLMM; $-0.0001 \pm 0.01 ; z=0.01, P=1 ; G L M M ;-0.02 \pm 0.02 ; z=-1, P=0.33$; GLMM; $0.0004 \pm 0.02 ; z=0.02, P=1$ and GLMM; $-0.001 \pm 0.01 ; z=$ $-0.09, P=0.9$ respectively). However, the number of seeds of grasses increased significantly in soils with depth greater than 10 cm (GLMM; $0.04 \pm 0.02 ; z=2.09, P=0.04$ ).

\section{DISCUSSION}

Since the middle of the 20th century, arid and dry areas have increased considerably at global scales and climate models project increases for the 21 st century. ${ }^{38}$ Moreover, short and long-term droughts will become, respectively, two and three times more common for most regions of the world. ${ }^{19}$ Although increases in drought frequency and intensity have been detected in many areas, ${ }^{3}$ there are also many uncertainties in model simulations because, in part, processes that have an effect on drought, such as vegetation dynamics, have not been integrated into the models. ${ }^{19}$ For grasslands, predictions show a reduction of cover and productivity by summer drought. ${ }^{39}$ However, evidence from climate manipulations shows that plant responses depend on the link between community dynamics and some soil properties. ${ }^{26}$ Moreover, components of ecosystems with key roles in community dynamics, such as seed banks, have not been sufficiently integrated into climate change studies. Persistent seed banks have been suggested to be crucial to the range expansion of species under environmental shifts. ${ }^{37}$ Moreover, they buffer the response of plant communities to altered precipitation regimes. ${ }^{36}$ Therefore, seed banks are considered key determinants of ecosystem resistance and resilience, ${ }^{27,40}$ based on the results of short-term climate manipulation experiments. ${ }^{17}$ Nevertheless, we have now demonstrated that seeds in calcareous grassland soils are not resistant to long-term summer drought.

Several mechanisms may explain the observed severe decline of calcareous grassland soil seed banks in response to drought. First, seed production may have been reduced. Drought increases fruit abortion, ${ }^{28}$ reduces productivity with potential consequences on yield, ${ }^{41}$ and reduces reproductive effort, ${ }^{42}$ which diminishes flowering. ${ }^{43}$ Drought favours clonal reproduction of some grassland species, which leads to a decrease in seed set. ${ }^{42,44}$ Second, germination patterns might have been altered. At least in some species, seed germination percentage is higher from plants growing in dry soils compared with those from wet soils. 42,45 Moreover, germination varies within species in response to soil water content, with some populations showing an increase in germination as soil moisture decreases. ${ }^{46,47}$ Drought may increase germination through maternal effects on seed dormancy, ${ }^{35}$ which, in some species, is reduced in seeds produced by plants growing in dry soils. ${ }^{35,48}$ In addition, seeds under drought stress show abrupt changes in seed abscisic acid (ABA) content during their development, and low sensitivity to exogenous ABA, which increases their germination. ${ }^{49}$ Third, rehydration of seeds in the soil is required to activate repair processes, ${ }^{50}$ and consequently to increase their persistence. ${ }^{51}$ Therefore, under long-term drought, exhaustion of seed physiological repair mechanisms could lead to loss of seed viability. ${ }^{50}$ Finally, drought also modifies the availability of nutrients in the soil. ${ }^{52}$ For instance, nitrogen $(\mathrm{N})$ uptake is smaller in some species growing in dry soils, ${ }^{53}$ which may then accumulate in the soil, with possible effects on the grassland seed bank ${ }^{54}$ and soil $\mathrm{pH}^{55}$ which in turn may have consequences for the persistence of seeds in grasslands soils. ${ }^{56}$ Previous studies at our experimental site showed that, comparing control and drought treatments, the mean plant $\mathrm{N}$ supply (the sum of plant-available nitrate and ammonium) was doubled after drought. $^{26}$

Sometimes, the response of the soil seed bank to climate variables may simply reflect the responses of the vegetation. In this case, the NMDS ordination suggests that compositional changes, at the community level, involving drought-resistant and sensitive species, species characteristic of wetter sites, ${ }^{26}$ and perhaps even the local genetic differentiation recorded in some species above-ground ${ }^{25}$ might be mirrored in the seed bank. Specifically, we found that both vegetation and seed bank showed no response to supplemental summer rainfall. In response to drought, the previously reported significant reduction in 
drought-sensitive species associated with moist soils ${ }^{26,29}$ was mirrored in the seed bank, although the effect of drought was greater on seed banks than on above-ground vegetation; ${ }^{25,26}$ species of moist soils, such as C. panicea and P. erecta, simply disappeared from the seed bank after 14 years of drought. In contrast, $C$. rotundifolia and $H$. pulchrum, species whose seed banks showed significant responses to drought, did not show any responses above-ground in a previous analysis of ours. ${ }^{26}$ Overall, our results indicate that vegetation cover responses are not the main driver of seed bank responses to altered precipitation regimes, suggesting that drought could have an effect on seed production and/or persistence. Unlike the reported changes in the above-ground vegetation ${ }^{26}$ which were mediated by soil depth, the changes in the seed bank were not affected by soil depth. Only the grass seed bank seemed to respond to soil depth, as evidenced by the presence of more seeds in the deepest soils. It is interesting to speculate that this increased abundance in deeper soils might be linked to the apparent resistance of the grass seed bank to reduced precipitation. Moreover, even single droughts events may have long-term and rather unpredictable effects on grassland vegetation. ${ }^{57}$ This suggests that it is important for future studies to measure the time-lags between the vegetation and seed banks responses to altered precipitation regimes, specifically in relation to soil heterogeneity. ${ }^{26}$

Overall, our results indicate that long-term summer drought has large negative effects on limestone grassland seed banks, and these cannot be explained simply by the effects on the vegetation. Furthermore, the reorganization by drought of the plant community at microsite level, mediated by soil depth, which is apparent above-ground, is much less evident in the seed bank. Therefore, seed bank responses are largely independent of changes in the vegetation, which suggests that seed production or persistence (or both) are reduced by long-term drought. Although our study cannot discriminate which mechanism is more affected by drought, an understanding of the mechanisms involved in these responses might help us to predict the vulnerability of grasslands to altered precipitation regimes. However, to the extent that resilience depends on the soil seed bank, calcareous grasslands may be less resilient to climate change than previously thought.

\section{METHODS}

\section{Study site}

The survey was conducted in the Buxton Climate Change Impacts Laboratory (BCCIL) at Harpur Hill, near Buxton, Derbyshire, UK. The experimental site is an ancient sheep pasture, unfertilized and steeply sloping $\left(35^{\circ}\right)$ located at latitude $53^{\circ} 20^{\prime}$ and 370 m.a.s.l. ${ }^{29}$ The grassland occurs on shallow soils on Carboniferous limestone with marked variation in soil depth at fine spatial scales. ${ }^{26}$ The infertile soils of this calcareous grassland support a species-rich plant community dominated by longlived, slow-growing evergreen species. ${ }^{29}$ The site is currently fenced, but was historically grazed by sheep and a small number of cattle and horses. To preserve grazing effects, since 1994 the site has been cut in October to a height of $4-5 \mathrm{~cm}$ and cut material removed. ${ }^{29}$

\section{The long-term precipitation change plots}

Three types of plots were sampled. (1) Summer drought (intercepted rainfall): this treatment eliminates rainfall to the plots from July to August. Summer drought has been imposed since 1994 using mobile, semitransparent shelters. The treatment was applied to the plots annually until 2004, after this date the treatment was applied every other year. ${ }^{29}$ (2) Supplemented summer rainfall (watered): additional deionised water was added to the plots regularly from June to September since 1994. This addition is equivalent to a $20 \%$ increase in the 10-year Buxton average precipitation (1972-1982). ${ }^{29}$ (3) Control plots, which were left untreated (ambient conditions). The climate change treatments were applied in a fully randomized block design replicated five times. Each replicate block consisted of $3 \times 3 \mathrm{~m}$ plots. Within each $3 \times 3 \mathrm{~m}$ plot a central area of $2.5 \times$ $2.5 \mathrm{~m}$ was used for sampling to minimise edge effects.
Seed bank sampling and characterization

For seed bank sampling, the central $2.5 \times 2.5 \mathrm{~m}$ area was subdivided in a grid of 25 subplots of $50 \times 50 \mathrm{~cm}$. Ten of these were randomly selected for soil sampling, with one core per chosen subplot extracted. Soil sampling was carried out in April 2008, after natural winter stratification and, before spring germination and seed set. Soil cores, $2.5 \mathrm{~cm}$ in diameter, were taken either to $20 \mathrm{~cm}$ or until the bedrock was reached. The samples were subdivided into $2 \mathrm{~cm}$ depth intervals to analyse the effects of sample depth. In addition, soil depth was measured at each seed bank sampling point by using a $1 \mathrm{~m}$ auger to analyse any possible effect of soil depth variation. The total number of soil samples was 524 and the total volume of soil sampled was $5144 \mathrm{~cm}^{3}$.

Seed bank characterization took place following the recommendations of Thompson et al. ${ }^{58}$ The seedling emergence method was used to characterise the seed bank. First, the vegetative plant parts were removed from soil samples. ${ }^{58} \mathrm{Next}$, the samples were sieved $(2.8 \mathrm{~mm}, 2 \mathrm{~mm}$ and 710 $\mu \mathrm{m})$ and all soil sieved was spread in germination trays in a layer of 1-3 $\mathrm{mm}$ on top of compost (Levington Professional Growing Medium-M3 High Nutrient: peat based, standard $\mathrm{pH}(5.5-6)$ and low conductivity (450-550 $\mu \mathrm{s})$. In addition, 100 germination trays were filled with compost only to test for seed contamination. Trays were randomly distributed in a greenhouse and maintained under $16 \mathrm{~h}$ - photoperiod with a temperature of $10^{\circ} \mathrm{C}$ (night) and $20^{\circ} \mathrm{C}$ (day). All trays were watered daily from below with tap water. Seedling emergence was recorded weekly from May 2008 to February 2009. Seedlings were removed soon after emergence, planted in new pots and identified to species level.

\section{Vegetation characterization}

Vegetation data were collected in June 2008. Eight permanent quadrats (two concentric squares $10 \times 10 \mathrm{~cm}$ and $20 \times 20 \mathrm{~cm}$ ) were located in each plot. Soil depth was measured at 9 points within each quadrat. These sampling points correspond to the centre and the corners of two concentric squares. The mean soil depth by quadrat ( 9 points measured in each quadrat) was used to calculate the mean soil depth per block. In the $10 \times 10 \mathrm{~cm}$ quadrats, total cover of each higher plant species was estimated by using a scale of five cover classes, from 0 to $5(0: 0 \% ; 1: \leq$ $5 \%$ cover; $2: 6-25 \%$; 3:26-50\%; 4:51-75\%; 5:76-100\%) was used.

\section{Statistical analysis}

All statistical analyses and figures were performed in R. $^{59}$ The seed bank response variables were number of species, total number of seeds, number of seeds of each functional group (forbs, grasses and sedges) and number of seeds of the two most abundant species $(H$. pulchrum and $C$. rotundifolia). GLMMs were fitted using the R-package Ime4. ${ }^{59,60}$ All models were fitted with precipitation treatment (summer drought, summer rainfall and control), depth of the sample and soil depth as the fixed effects and block, plot and subplot as a random effect with the Poisson error distributions. To visualize changes in the seed bank species composition among treatments, a non-metric multidimensional scaling (NMDS) ordination was rendered using a Bray-Curtis distance measure. Analyses were performed using the meta-MDS function in the vegan package in $\mathrm{R}^{59,61}$ In addition, the envfit function in the vegan package in $\mathrm{R}^{59,61}$ was run on data to determine if treatment was correlated across the NMDS ordination. Treatment was fitted as a factor to the NMDS ordination. $P$ values were estimated from the comparison of correlation coefficients with those generated from 1000 random permutations of the data.

To compare above-ground vegetation and seed bank similarity we calculated matrices using the Bray-Curtis distance. To visualize changes in the species composition among both communities, a non-metric multidimensional scaling (NMDS) ordination was performed using a Bray-Curtis distance measure. Analyses were performed using the meta-MDS function in the vegan package in $R^{59,61}$ In addition, the envfit function in the vegan package in $\mathrm{R}^{59,61}$ was run on data to determine if treatment was correlated across the NMDS ordination. Treatment was fitted as a factor to the NMDS ordination. $P$ values were estimated from the comparison of correlation coefficients with those generated from 1000 random permutations of the data. To avoid differences in sampling scales, for each species seed bank data were converted to relative abundance and vegetation data to relative cover. The first was calculated, for each treatment, by dividing the total number of seeds of each species per block by the total number of seeds recorded in every block. The relative vegetation cover was calculated first by summing the cover class data of each species per block of each precipitation treatment, then, by dividing this value by the total cover class 
data of all species per block. To compare species richness between seed bank and vegetation above-ground, GLMs with the Poisson error distributions were used. Models included the explanatory variables: precipitation treatments and the number of species above-ground. To test if the above-ground cover affects seed bank total abundance, GLMs with the Gaussian errors distributions were fitted to seed bank and vegetation relative abundance data. Forty-six species recorded above and below-ground were used in the analysis. Moreover, the effect of aboveground cover on the number of seeds of the two most abundant species recorded in the seed bank ( $H$. pulchrum and $C$. rotundifolia) was also analysed using GLMs with the Gaussian errors distributions. This analysis was also based on relative abundance data. Models included the explanatory variables: precipitation treatments and above-ground relative abundance. Above-ground cover data of the two most abundant species recorded in the seed bank ( $H$. pulchrum and $C$. rotundifolia) were analysed using GLMs with the Gaussian errors distributions. Models included the explanatory variables: precipitation treatments and soil depth.

\section{Data availability}

The data that support the findings of this study are available in the Institutional Repository of Pontificia Universidad Javeriana, http://hdl. handle.net/10554/21588.

\section{ACKNOWLEDGEMENTS}

This study was supported by the Programme AIßan, the European Union Programme of High Level Scholarships for Latin America, scholarship No. (E07D400528CO) and Pontificia Universidad Javeriana (DJE-009-07) (to S.B.). The field Buxton Climate Change Experiment was funded by U.S. National Science Foundation grant DEB0716360 to J.D.F. and was initially established with funding from the UK Natural Environment Research Council. Space and logistical support was provided by the Health and Safety Laboratory, Harpur Hill, Derbyshire, UK.

\section{AUTHOR CONTRIBUTIONS}

S.B. collected the soil samples and ran the seed bank germination study data. S.B. and K.T. identified the seedling species. J.P.G. and J.D.F. collected the vegetation data. S.B, S.C. and M.R. analysed the data. A.P.A. has maintained the plots over the years. S.B. prepared the manuscript and wrote the paper with contributions from all the authors.

\section{ADDITIONAL INFORMATION}

Supplementary information accompanies the paper on the npj Climate and Atmospheric Science website (https://doi.org/10.1038/s41612-017-0007-3).

Competing interests: The authors declare no competing financial interests.

Publisher's note: Springer Nature remains neutral with regard to jurisdictional claims in published maps and institutional affiliations.

\section{REFERENCES}

1. Field, C. B. et al. Technical Summary. In Climate Change 2014: Impacts, Adaptation, and Vulnerability. Part A: Global and Sectoral Aspects. Contribution of Working Group II to the Fifth Assessment Report of the Intergovernmental Panel on Climate Change (eds Field, C. B. et al.) 35-94 (Cambridge University Press, Cambridge, UK and New York, NY, USA, 2014).

2. Valkó, O. et al. Ecology and conservation of steppes and semi-natural grasslands. Hacquetia 15, 5-14 (2016).

3. Settele, J. et al. Terrestrial and inland water systems. In Climate Change 2014: Impacts, Adaptation, and Vulnerability. Part A: Global and Sectoral Aspects. Contribution of Working Group II to the Fifth Assessment Report of the Intergovernmental Panel on Climate Change (eds Field, C. B. et al.) 271-359 (Cambridge University Press, Cambridge, UK and New York, NY, USA, 2014).

4. Cleland, E. E. et al. Sensitivity of grassland plant community composition to spatial vs. temporal variation in precipitation. Ecology 94, 1687-1696 (2013).

5. White, S. R., Bork, E. W., Karst, J. \& Cahill, J. F. Similarity between grassland vegetation and seed bank shifts with altered precipitation and clipping, but not warming. Community Ecol. 13, 129-136 (2012).

6. Dukes, J. S. et al. Responses of grassland production to single and multiple global environmental changes. PLoS Biol. 3, e319 (2005).
7. Dangal, S. R. et al. Synergistic effects of climate change and grazing on net primary production of Mongolian grasslands. Ecosphere 7, e01274 (2016).

8. Cang, F. A., Wilson, A. A. \& Wiens, J. J. Climate change is projected to outpace rates of niche change in grasses. Biol. Lett. 12, 20160368 (2016).

9. Hutchings, M. J. \& Stewart, A. J. A. Calcareous grasslands. In Handbook of Ecological Restoration. Restoration in Practice, Vol. 2. (eds Perrow, M. R. \& Davy, A. J.) 419-444 (Cambridge University Press, Cambridge, UK, 2002).

10. Van Looy, K., Lejeune, M. \& Verbeke, W. Indicators and mechanisms of stability and resilience to climatic and landscape changes in a remnant calcareous grassland. Ecol. Indic. 70, 498-506 (2016).

11. Fagan, K. C., Pywell, R. F., Bullock, J. M. \& Marrs, R. H. Do restored calcareous grasslands on former arable fields resemble ancient targets? The effect of time, methods and environment on outcomes. J. Appl. Ecol. 45, 1293-1303 (2008).

12. Craine, J. M. et al. Global diversity of drought tolerance and grassland climatechange resilience. Nat. Clim. Chang. 3, 63-67 (2012).

13. Ooi, M. K. Seed bank persistence and climate change. Seed Sci. Res. 22, S53-S60 (2012).

14. Gorden, N. L. S. et al. Geographic patterns of seed mass are associated with climate factors, but relationships vary between species. Am. J. Bot. 103, 60-72 (2016).

15. Walck, J. L., Hidayati, S. N., Dixon, K. W., Thompson, K. \& Poschlod, P. Climate change and plant regeneration from seed. Glob. Chang. Biol. 17, 2145-2161 (2011).

16. Ooi, M. K. J., Auld, T. D. \& Denham, A. J. Climate change and bet hedging: interactions between increased soil temperatures and seed bank persistence. Glob. Chang. Biol. 15, 2375-2386 (2009).

17. Akinola, M. O., Thompson, K. \& Buckland, S. M. Soil seed bank of an upland calcareous grassland after 6 years of climate and management manipulations. J. Appl. Ecol. 35, 544-552 (1998).

18. Leishman, M. R., Masters, G. J., Clarke, I. P. \& Brown, V. K. Seed bank dynamics: the role of fungal pathogens and climate change. Funct. Ecol. 14, 293-299 (2000).

19. Sheffield, J. \& Wood, E. F. Projected changes in drought occurrence under future global warming from multi-model, multi-scenario, IPCC AR4 simulations. Clim. Dyn. 31, 79-105 (2008).

20. Wagner, M., Pywell, R. F., Knopp, T., Bullock, J. M. \& Heard, M. S. The germination niches of grassland species targeted for restoration: effects of seed pretreatments. Seed Sci. Res. 21, 117-131 (2011).

21. Fay, P. A. \& Schultz, M. J. Germination, survival, and growth of grass and forb seedlings: effects of soil moisture variability. Acta Oecol. 35, 679-684 (2009).

22. Petrů, M. \& Tielbörger, K. Germination behaviour of annual plants under changing climatic conditions: separating local and regional environmental effects. Oecologia 155, 717-728 (2008).

23. Mordecai, E. A. Soil moisture and fungi affect seed survival in California grassland annual plants. PLOS ONE 7, e39083 (2012).

24. Schafer, M. \& Kotanen, P. M. The influence of soil moisture on losses of buried seeds to fungi. Acta Oecol. 24, 255-263 (2003).

25. Ravenscroft, C. H., Fridley, J. D. \& Grime, J. P. Intraspecific functional differentiation suggests local adaptation to long-term climate change in a calcareous grassland. J. Ecol. 102, 65-73 (2014).

26. Fridley, J. D., Grime, J. P., Askew, A. P., Moser, B. \& Stevens, C. J. Soil heterogeneity buffers community response to climate change in species-rich grassland. Glob. Chang. Biol. 17, 2002-2011 (2011).

27. Godfree, R. et al. Multiscale topoedaphic heterogeneity increases resilience and resistance of a dominant grassland species to extreme drought and climate change. Glob. Chang. Biol. 17, 943-958 (2011).

28. Davison, R. et al. Demographic effects of extreme weather events on a short-lived calcareous grassland species: stochastic life table response experiments. J. Ecol. 98, 255-267 (2010).

29. Grime, J. P. et al. Long-term resistance to simulated climate change in an infertile grassland. Proc. Natl. Acad. Sci. USA 105, 10028-10032 (2008).

30. Silvertown, J. et al. Environmental myopia: a diagnosis and a remedy. Trends Ecol. Evol. 25, 556-561 (2010).

31. Vandvik, V., Klanderud, K., Meineri, E., Måren, I. E. \& Töpper, J. Seed banks are biodiversity reservoirs: species-area relationships above versus below ground. Oikos 125, 218-228 (2016).

32. Kalamees, R. \& Zobel, M. The role of the seed bank in gap regeneration in a calcareous grassland community. Ecology 83, 1017-1025 (2002).

33. Bradbury, D. et al. The role of fire and a long-lived soil seed bank in maintaining persistence, genetic diversity and connectivity in a fire-prone landscape. J. Biogeogr. 43, 70-84 (2016).

34. Kalamees, R., Püssa, K., Zobel, K. \& Zobel, M. Restoration potential of the persistent soil seed bank in successional calcareous (alvar) grasslands in Estonia. Appl. Veg. Sci. 15, 208-218 (2012). 
35. Baskin, C. C. \& Baskin, J. M. Seeds. Ecology, Biogeography, and Evolution of Dormancy and Germination. (Elsevier/Academic Press, San Diego, USA, 2014).

36. Tielbörger, K. et al. Middle-Eastern plant communities tolerate 9 years of drought in a multi-site climate manipulation experiment. Nat. Commun. 5, 5102 (2014).

37. Estrada, A. et al. Species' intrinsic traits inform their range limitations and vulnerability under environmental change. Glob. Ecol. Biogeogr. 24, 849-858 (2015)

38. Dai, A. Drought under global warming: a review. WIREs Clim. Change 2, 45-65 (2011).

39. Hufkens, K. et al. Productivity of North American grasslands is increased under future climate scenarios despite rising aridity. Nat. Clim. Chang. 6, 710-714 (2016).

40. Enright, N. J., Fontaine, J. B., Lamont, B. B., Miller, B. P. \& Westcott, V. C. Resistance and resilience to changing climate and fire regime depend on plant functional traits. J. Ecol. 102, 1572-1581 (2014).

41. Bloor, J. M., Pichon, P., Falcimagne, R., Leadley, P. \& Soussana, J. F. Effects of warming, summer drought, and $\mathrm{CO} 2$ enrichment on aboveground biomass production, flowering phenology, and community structure in an upland grassland ecosystem. Ecosystems 13, 888-900 (2010).

42. Gao, R., Yang, X., Liu, G., Huang, Z. \& Walck, J. L. Effects of rainfall pattern on the growth and fecundity of a dominant dune annual in a semi-arid ecosystem. Plant Soil. 389, 335-347 (2015).

43. Craine, J. M., Towne, E. G. \& Nippert, J. B. Climate controls on grass culm production over a quarter century in a tallgrass prairie. Ecology 91, 2132-2140 (2010).

44. O'connor, T. G. Composition and population responses of an African savanna grassland to rainfall and grazing. J. Appl. Ecol. 31, 155-171 (1994).

45. Evans, C. E. \& Etherington, J. R. The effect of soil water potential on seed germination of some British plants. New Phytol. 115, 539-548 (1990).

46. Gazanchian, A., Sima, K. K., Nayer, A., Malboobi, M. A. \& Majidi Heravan, E. Relationships between emergence and soil water content for perennial cool-season grasses native to Iran. Crop. Sci. 46, 544-553 (2006).

47. Rohollahi, I. et al. Evaluation of seedling emergence and relative DNA content under dry soil conditions of wild Festuca arundinacea populations collected in Iran. Grassl. Sci. 61, 6-14 (2015).

48. Wright, K. J., Seavers, G. P., Peters, N. C. B. \& Marshall, M. A. Influence of soil moisture on the competitive ability and seed dormancy of Sinapis arvensis in spring wheat. Weed Res. 39, 309-317 (1999).

49. Hilhorst, H. W. A critical update on seed dormancy. I. Primary dormancy. Seed Sci. Res. 5, 61-73 (1995).

50. Kranner, I., Minibayeva, F. V., Beckett, R. P. \& Seal, C. E. What is stress? Concepts, definitions and applications in seed science. New Phytol. 188, 655-673 (2010).

51. Long, R. L. et al. The ecophysiology of seed persistence: a mechanistic view of the journey to germination or demise. Biol. Rev. 90, 31-59 (2015).
52. Köhler, B., Ryser, P., Güsewell, S. \& Gigon, A. Nutrient availability and limitation in traditionally mown and in abandoned limestone grasslands: a bioassay experiment. Plant Soil. 230, 323-332 (2001).

53. Durand, J. L., Gonzalez-Dugo, V. \& Gastal, F. How much do water deficits alter the nitrogen nutrition status of forage crops? Nutr. Cycl. Agroecosyst. 88, 231-243 (2010).

54. Basto, S. et al. Long-term nitrogen deposition depletes grassland seed banks. Nat. Commun. 6, 6185 (2015).

55. Carroll, J. A., Caporn, S. J., Johnson, D., Morecroft, M. D. \& Lee, J. A. The interactions between plant growth, vegetation structure and soil processes in seminatural acidic and calcareous grasslands receiving long-term inputs of simulated pollutant nitrogen deposition. Environ. Pollut. 121, 363-376 (2003).

56. Basto, S., Thompson, K. \& Rees, M. The effect of soil pH on persistence of seeds of grassland species in soil. Plant Ecol. 216, 1163-1175 (2015).

57. Haddad, N. M., Tilman, D. \& Knops, J. M. Long-term oscillations in grassland productivity induced by drought. Ecol. Lett. 5, 110-120 (2002).

58. Thompson, K., Bakker, J. P. \& Bekker, R. M. The Soil Seed Banks of North West Europe: Methodology, Density and Longevity (Cambridge University Press, Cambridge, UK, 1997).

59. R Core Team. R: A Language and Environment for Statistical Computing (R Foundation for Statistical Computing, 2016), http://www.R-project.org/.

60. Bates, D., Maechler, M., Bolker, B. \& Walker, S. Ime4: Linear Mixed-Effects Models Using Eigen and S4 (R package version 1.0-4, 2013), http://cran.r-project.org/ package $=$ Ime $4 /$.

61. Oksanen, J. et al. Vegan: Community Ecology Package (R package version2.0-10, 2013), http://cran.r-project.org/package=vegan/.

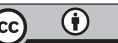

Open Access This article is licensed under a Creative Commons Attribution 4.0 International License, which permits use, sharing, adaptation, distribution and reproduction in any medium or format, as long as you give appropriate credit to the original author(s) and the source, provide a link to the Creative Commons license, and indicate if changes were made. The images or other third party material in this article are included in the article's Creative Commons license, unless indicated otherwise in a credit line to the material. If material is not included in the article's Creative Commons license and your intended use is not permitted by statutory regulation or exceeds the permitted use, you will need to obtain permission directly from the copyright holder. To view a copy of this license, visit http://creativecommons. org/licenses/by/4.0/.

(c) The Author(s) 2018 